\title{
COVID-19 La transformación de la educación en el Ecuador mediante la inclusión de herramientas tecnológicas para un aprendizaje significativo
}

\section{COVID-19 The transformation of education in Ecuador through the inclusion of technolo- gical tools for meaningful learning}

\author{
Rojas-Londońo Orlando David ${ }^{1}$ \\ https://orcid.org/0000-0003-2046-6636 \\ José Luis Díaz-Mora ${ }^{2}$ \\ https://orcid.org/0000-0003-2054-7380 \\ Universidad Tecnológica Indoamérica, Ecuador
}

Recibido: 30-06-2020

Aceptado: 19-08-2020

\section{Cita Recomendada}

Rojas-Londoño, O. \& Diaz-Mora, J. (2020). COVID-19 La obligación al cambio; Transformación de la educación mediante la inclusión de herramientas tecnológicas para un aprendizaje significativo. Hamut'ay, 7 (2), 64-74.

http://dx.doi.org/10.21503/hamu.v7i2.2134

\section{RESUMEN}

El COVID-19 ha provocado cambios sustanciales en todas las aristas sociales, al generar en las personas una obligación al cambio desde lo humano, lo económico y lo cultural, siendo el sector educativo uno de los que se vieron más afectados. En este sector, los docentes se vieron obligados a trasladar sus contenidos, metodologías y estrategias pedagógicas de lo presencial a lo virtual, lo que ha traído transformaciones en la educación mediante la inclusión de herramientas tecnológicas para un aprendizaje significativo, que pretende dinamizar el proceso de enseñanza para fomentar en los estudiantes la generación de su propio conocimiento y el convertirse en un ente activo. En el artículo se presenta una lista de herramientas tecnológicas que con adecuados enfoques pedagógicos pueden utilizarse en varios momentos del proceso de aprendizaje, con la finalidad de coadyuvar a que los docentes fomenten espacios potencializadores con un alto grado de interacción, dejando clases tradicionales y aplicando las tecnologías en esta sociedad del conocimiento. El estudio es el resultado de la investigación en repositorios de reseñas relevantes que están en la web, como muestra de una serie de herramientas valiosas para el campo educativo que evolucionaron a grandes pasos desde la llegada del COVID-19 y que han revolucionado el campo pedagógico, al incorporar competencias digitales en la Comunidad Educativa que antes no se desarrollaban. Al ser este un estudio documental, se presenta un compendio y un análisis minucioso de la literatura dentro de un periodo de 5 años en relación a la inclusión de la tecnología en el contexto educativo.

\footnotetext{
1 Master en Docencia Universitaria y Administración Educativa, Especialista en Diseño Curricular por competencias. Coordinador Académico de Posgrado en Educación. Docente investigador. E-mail: davidrojas@uti.edu.ec

2 Estudiante del Programa de Maestría en Educación mención Innovación y Liderazgo Educativo. Psicólogo Educativo de profesión. Investigador. E-mail: jose.luis890516@gmail.com
} 
Palabras clave: COVID-19, tecnología educativa, aprendizaje significativo, proceso de enseñanza-aprendizaje.

\begin{abstract}
COVID-19 has caused substantial changes in all social aspects, by generating in people an obligation to change from the human, economic and cultural aspects, with the education sector being one of those that were most affected. In this sector, teachers were forced to transfer their content, methodologies and pedagogical strategies from face-to-face to virtual, which has brought transformations in education through the inclusion of technological tools for meaningful learning, which aims to stimulate the process of learning. teaching to encourage students to generate their own knowledge and become an active entity. The article presents a list of technological tools that with appropriate pedagogical approaches can be used at various moments of the learning process, in order to help teachers, promote potentializing spaces with a high degree of interaction, leaving traditional classes and applying the same technologies in this knowledge society. The study is the result of research in repositories of relevant reviews that are on the web, as a sample of a series of valuable tools for the educational field that have evolved in great strides since the arrival of COVID-19 and that have revolutionized the pedagogical field, by incorporating digital competences in the Educational Community that were not developed before. As this is a documentary study, a compendium and a detailed analysis of the literature is presented within a period of 5 years in relation to the inclusion of technology in the educational context.
\end{abstract}

Keywords: educational technology, meaningful learning, teaching-learning process.

\section{INTRODUCCIÓN}

A causa de un virus el mundo se ha transformado cambiando costumbres, forma de vida, creencias e incluso la forma de alimentarse, cuidar la salud y el estado físico, cambios que se han generado en estos últimos meses, Alvites-Huamaní, (2020), pero sobre todo modificó el sistema educativo al pasar de una modalidad presencial a una virtual. Todo esto generó una reacción nunca antes vista, y así se tuvo que considerar a las competencias digitales como una parte integral del desarrollo y de la cohesión con los nuevos ecosistemas, a valorar lo que hacen las personas desde cada uno de sus ámbitos de trabajo, el entender que a veces lo único que era realmente importante y enriquecía el conocimiento era el compartir entre amigos, ese sentimiento de libertad que el Coronavirus o más conocido como COVID-19 despojó de un momento a toda la colectividad.
El COVID-19 un virus que se propagó por todo el mundo e hizo que las personas se enclaustraran en sus hogares para evitar contagios y pérdidas mortales. Este proceder hizo que toda la población mundial opte por otras alternativas para intentar seguir con sus actividades cotidianas, y es así que se empezó a utilizar las plataformas virtuales, las mismas que permitieron seguir cohesionando a las instituciones educativas con las familias, lo que ha generado la implantación de una enseńanza a distancia, y el aplicar metodologías online (OEI, 2020). Estos esfuerzos conllevan a que el sistema educativo cambie y en muchos casos evolucione hacia nuevos modelos educativos que abarcan todos los aspectos de la Web. 2.0, de la sociedad del conocimiento hasta llegar en algunos casos a cambiar de un modelo constructivista a un modelo conectivista con las bondades y restricciones que esto conlleva. 
Por ello se requiere dialogar sobre las distintas herramientas tecnológicas que, a causa de la pandemia, se han puesto disposición de los educadores para establecer mejores estrategias de enseñanza, que faciliten una dinámica de aprendizaje más efectivo sin perder la inter, multi y transdisciplinariedad de los diferentes contenidos que se trabajan, en algunos potencializando el aprendizaje significativo.

Con este trabajo se busca compartir información acerca de algunas plataformas y programas relacionados a la educación; información conocida a nivel mundial que debe ser divulgada ampliamente y también el marco normativo sobre cómo adecuarse ante el COVID-19, la misma que obligó a tomar medidas que garanticen una educación de calidad y que son necesarias para avanzar en las distintas áreas pedagógicas, como los aspectos curriculares, didácticos y metodológicos.

\section{Método}

Este artículo de revisión presenta un fundamento teórico y conceptual, con un análisis de tipo descriptivo-exploratorio de los datos obtenidos a través del proceso de investigación de artículos indexados tomados como referencia en el análisis de este estudio (Hernández \& Sampieri, 2010). Es producto de la búsqueda minuciosa en importantes bases de datos, como son Elservier, SciElo, DOAJ, repositorios virtuales nacionales e internacionales; así como en Google Scholar. Para la revisión se emplearon algunas palabras claves como: 1. COVID -19, 2. Las Tecnologías de la Comunicación e Información, 3. Herramientas Digitales y 4. Aprendizaje Significativo.

Los análisis y la revisión de la literatura se realizaron desde los años 2015 al 2020, pero se ha considerado literatura anterior por la relevancia del tema en cuanto a la tendencia del uso de la tecnología. Siendo este un estudio documental, después de realizar la exploración teórica, se organizó el artículo estructurándolo desde definiciones específicas, desde la contextualización de la pandemia del COVID-19 y como esta fue cambiando el modelo del sistema educativo con la obligatoriedad de in- corporar herramientas tecnológicas.

\section{Contextualizando al COVID-19 en el ámbito educacional}

Entender que esta pandemia ha afectado la actividad Psicológica de las personas, así lo señala Vera-Villarroel, (2019), que afirma: Por otra parte, esta enfermedad ha puesto en evidencia tal como lo menciona la OMS: la salud no solo abarca el bienestar biológico, pues como se lo define desde décadas atrás, también es necesario tener una homeostasis a nivel psicológico, emocional y social. Si tomamos esta aproximación parece necesario entonces analizar en detalle esta enfermedad desde un punto de vista psicológico y de qué modo la psicología puede aportar y transformarse en una disciplina esencial en el combate del COVID-19.

Desde mediados de marzo del 2020 en todo el mundo empezó a utilizar herramientas tecnológicas para afrontar la cuarentena que sufre el mundo desde la propagación a nivel mundial de un virus llamado SARS-CoV-2 (más conocida como enfermedad del COVID-19). Según la UNESCO, 1500 millones de discentes a nivel global han sido afectados en la forma de recibir sus aprendizajes. Así se presume que un 89,4\%, de toda la población estudiantil también ha experimentado un cambio drástico en cómo debe forjar sus saberes. Con lo cual, cabe recalcar que antes de la pandemia, ya había muchos estudiantes que en la modalidad presencial tenían complicaciones para adquirir un dominio en las habilidades fundamentales para la vida. El Banco Mundial, exponía indicadores, los cuales mencionaban que la "pobreza en los aprendizajes" que tienen los niños de 10 años, con unos porcentajes del $53 \%$ de la población, los cuales no pueden leer, ni comprender un texto simple, estos porcentajes están en los países a los que se les ha dominado de bajos y medianos ingresos. Todo esto, ya se evidenciaba antes de la crisis provocada por la cuarentena, y ésta puede empeorar los resultados si no se logra actuar de una manera pertinente. (Cotino, 2020; Saavedra, 2020)

Lo mencionado anteriormente genera la siguiente interrogante: ¿cómo puede influir esta crisis a las niñas, niños y jóvenes de todo el mundo? Y es así, que, se tiene que considerar en primer lugar que 
se podría tener una pérdida de aprendizajes en los discentes, luego de eso probablemente se generaría una tasa de deserción más elevada según los datos estadísticos: el $37 \%$ de la población, no termina sus estudios secundarios (Banco Interamericano de desarrollo, 2018).

Sin embargo, pese a las estadísticas mencionadas, se requiere enfatizar que, gracias a las Tecnologías Educativas (TE), la población mundial que tenga conectividad está a un clic de la información y puede acceder más rápidamente a comprender lo que requiera, es decir, las TE generan una democratización en el conocimiento. Con lo cual, cada individuo tiene la facilidad de forjar sus propios saberes $y$ de forma más autónoma (Ardini, 2020).

Es necesario tomar en cuenta el componente psicológico y todas las afectaciones que esto conlleva, el adaptarse a un nuevo proceso así lo menciona González, Londoño, Vásconez \& Cerón, (2019), los factores más relevantes, a tomarse en consideración en el campo de la pedagogía son las leyes de aprendizaje, las mismas que están enfocadas en que el estudiante requiere un adecuado ambiente para su aprendizaje, pues esto permite que los procesos cognitivos estén centrados en aprender de manera positiva, y así se puede regular también su conducta, de esa forma alcanzar un mejor aprovechamiento y una mejor adaptación a su entorno educativo. Este entorno educativo trasladado a los hogares y mediante un sistema de educación en línea busca cubrir todas las inquietudes propias del proceso de enseñanza aprendizaje.

El internet brinda un campo muy amplio en lo que concierne a educación, ya que este deja en un alto nivel de libertad para participar en el proceso de autoaprendizaje. Cabe recalcar que es una herramienta cuyo uso es más fácil para los jóvenes, pues ellos están acostumbrados a esa interacción, es decir son nativos cibernéticos; y son los adultos los que en muchas ocasiones y reiteradamente presentan complicaciones en el uso adecuado de éstas herramientas ( $y$ suele ser en un mayor grado de complejidad en adaptarse a estas, cuando se trata de personas de edades avanzadas), ya que son quienes menos experiencias y conocimientos tienen en el uso de las mismas y por lo tanto desconocemos de las ventajas, desventajas y posibles aperturas de aprendizajes que facilitan (Buxarrais \& Ovide, 2011).

Antes, usar y acercarse a las Tecnologías Educativas era opcional y en algunos casos una herramienta en el aula. Sin embargo, con la propagación de la pandemia se hizo obligatorio y un canal indispensable, el cual permite ese dialogo docentes - estudiantes, es decir, que en la actualidad tener dominio y conocimiento sobre el uso adecuado de las plataformas es imprescindible, y hay que tener en cuenta que no solo hay que tener entendimiento en las aplicaciones más usuales y conocidas, sino también en otras herramientas tecnológicas que permitan una mejor interacción en el aula virtual, que concedan generar un aprendizaje dinámico y significativo. De esta forma los docentes están en la encrucijada de exponer sus habilidades tecnológicas: conocer cómo usar las TE, adaptar su clase a la modalidad virtual, captar la atención de los estudiantes, generar un dialogo adecuado y constante con los padres de familia, para que ellos desde la cercanía con sus hijos, dialoguen y fomenten la responsabilidad de estos últimos. (Ardini, 2020)

Sin embargo, también es necesario destacar que a pesar de las facilidades que brinda el estudio virtual, hay limitantes: el acceso al internet o el tener algún aparato tecnológico, son requisitos fundamentales para permitir acercarse a las oportunidades comentadas anteriormente. Según global digital (2020) 60\% de la población mundial tiene acceso a internet, y el $67 \%$ de la población utiliza un teléfono inteligente. Es decir que aproximadamente un $40 \%$ de toda la población mundial está excluida del espacio cibernético, todo esto puede llegar a exacerbar las desigualdades, las mismas que han estado arraigadas por muchos años, y si no se toman las debidas precauciones del caso, cada día habrá más estudiantes que abandonen sus estudios. Con la crisis que se generó con la aparición del COVID-19, es necesario fomentar medidas especiales que busquen la equidad e igualdad para todos los estudiantes, de esa forma se puede contrarrestar las desigualdades que tiene la sociedad. (Global Digital, 2020; Cotino, 2020).

Y si nos proyectamos a futuro, desde la educación inicial, básica y media con una visión a la inserción en el sistema de educación superior, tendrá 
una consecuencia que la introducción de las herramientas técnológicas les permiten a los estudinates alcanzar mayores competencias en sus primeros ańos de escolaridad y luego por cuestiones netamente metodológicas deban retroceder por un sistema academista catedrático, es fundamental hacer énfasis en lo descrito por, Dillon, Rojas, Robalino, \& Maldonado, (2020), la calidad y mejora continua de la educación superior debe estar basada en ejes fundamentales que impulsen el desarrollo de competencias ancladas a un perfil de salida y todo su procesos como graduación y titulación, en todas carreras del ámbito universitario. (p.28)

\section{Disposiciones legales para el desarrollo del sis- tema educativo en Ecuador}

Hasta el momento no se ha encontrado cura para el COVID-19, por tal razón es de suma importancia evitar la propagación de la enfermedad por lo que los gobiernos de distintos países han tomado medidas de control y prevención. El gobierno ecuatoriano declaró en estado de emergencia sanitaria decretando las siguientes medidas:

- Suspensión de Clases Escolares presenciales Clases Virtuales

- Suspensión de trabajo presencial - Teletrabajo

- No circulación de Vehículos

- Cierre de Locales comerciales,

- Suspensión de Vuelos Internacionales y Nacionales

- Cierre de eventos sociales en donde exista acumulación de personas.

Estas decisiones en macro contexto, cambiaron drásticamente la rutina normal de las familias y las personas lo que dio como resultado un confinamiento en cada hogar, es así que los hábitos diarios tuvieron que ser transformados y adaptados a la realidad de estudiar, trabajar y cumplir las actividades familiares y de casa al mismo tiempo. Esto ha dado como resultado una variedad de problemas y conflictos referente a que ya no se tiene un horario determinado para cada actividad en donde antes claramente se podía separar las actividades escolares, de las tareas de trabajo y hogar.

Actualmente en el Ecuador debido de la crisis sa- nitaria por el COVID-19, se está utilizando a nivel de educación media y superior medios de comunicación virtuales, la accesibilidad a internet es un problema latente y constante, solo basta observar los boletines y datos arrojados por el INEC (2018) que se describe en la zona y población para el análisis del uso de redes sociales en el contexto de la educación media y superior correspondiente al territorio ecuatoriano, se determinó de tres parámetros de observación, los cuales fueron obtenidos del Instituto de Estadísticas y Censos (INEC) en lo que se refiere a las TE, estos parámetros se detallan:

Equipamiento tecnológico del hogar. Se analizó el comportamiento de la sociedad ecuatoriana, con relación al equipamiento tecnológico del hogar, y su evolución a través del tiempo, actualmente el 24\% de los hogares del Ecuador posee un dispositivo electrónico (laptop, Tablet, computadora de escritorio). Hogares con acceso a Internet, según la encuesta del uso de tecnología digital, se estableció que el porcentaje de hogares que accedieron a este servicio se ubicó en el $37 \%$ a escala nacional, siendo el área rural la de menor acceso con 16 por ciento de accesibilidad. Uso de Redes Sociales, según el INEC (2018) el uso de redes sociales de ecuatorianos mayores a 12 años, fue del 66\%, se considera este porcentaje dentro de la población económicamente activa y discentes que pertenecen a una educación media y superior, los valores se obtuvieron en millones de personas para redes sociales de mayor uso. (Facebook 12M, WhatsApp 13M).

A pesar de las dificultades mencionadas anteriormente, El Ministerio de Educación ecuatoriano, tuvo que suspender las clases presenciales desde mediados del mes marzo del presente ańo y optar por las clases virtuales, todo esto fue un cambio abrupto, pero necesario, la predisposición fue tomada por todas las instituciones: particulares, fiscales y municipales con la finalidad de precautelar la salud de toda la comunidad educativa. Desde el 17 de marzo, se optó por trabajar en las aulas virtuales con los estudiantes. Sin embargo, las autoridades recalcaron que se empezó a suscitar inconvenientes en las actividades virtuales y que estaban buscando soluciones para trabajar con los estudiantes y docentes, pues varios, no tienen conectividad de internet o aparatos tecnológicos adecuados en sus hogares, los cuales permitan la 
interacción cibernética; y que se recuerde que esta modalidad se la optó para precautelar la formación académica, y que no se vea afectada la misma (Ministerio de Educación del Ecuador , 2020a).

\section{Planificación de los aprendizajes con la inclu- sión de herramientas tecnológicas}

El Ministerio de Educación del Ecuador-MinEduc, hizo lineamientos que orientaban cómo se deberían dar las clases virtuales y sobre todo se buscó enfatizar en la importancia de la planificación curricular, la cual asegura que el proceso de aprendizaje sea continuo, pertinente y en especial que sea dosificado. Todo este procedimiento permite que los docentes puedan organizar y dirigir de una manera adecuada cada una de las necesidades educativas que tienen los estudiantes. En una época de emergencia la planificación es necesaria y gracias a ella los docentes pueden generar rutinas y actividades coherentes, claras y mejorables de esa forma los beneficiados son los estudiantes. Es necesario que el docente busque generar en sus estudiantes dudas sobre cómo tener un autocuidado en esta pandemia, (Ministerio de Educación del Ecuador, 2020b, p.10). Con la emergencia sanitaria se requiere formar estudiantes que se desempeñen en una sociedad que está en constantes cambios radicales, de la misma forma el docente debe cambiar su forma de comportarse, es así, que todos los docentes deben comenzar a capacitarse en el dominio de las herramientas tecnológicas, y seguir aumentando su vagaje tecnológico, pues los estudiantes tienen facilidades para obtener información en el Internet y así, ellos también están en actualización.

El currículo para la emergencia también se ha enfocado en elementos como: informar qué es el COVID-19 y cómo convivir con el virus, el cuidado ambiental, la interculturalidad, los derechos humanos y hacer un enfasis en lo que es la ciudadanía global. Cabe recordar, que en todo momento, los docentes deben realizar una educación en valores tales como responsabilidad, solidaridad, empatía, tolerancia, manejo de emociones y tenciones, saber tomar de decisiones adecuadas, habilidades comunicativas, asertividad, resolución de conflictos, etc. de esa forma se busca generar una educación interdisciplinar, permitiendo que las ideas centrales de varias asignaturas interactuen entre sí, con lo cual, se genera el desarrollo del currículo de una manera abierta, flexible y contextualizada. (Ministerio de Educación del Ecuador, 2020b, pp.8 -10)

\section{Estrategias metodológicas pensando en la inte- racción e interactividad}

Las metodologías que se usan son aquellas que impelen a los estudiantes a ser los creadores de su propio aprendizaje, los cuales están enfocados en el respeto, la dignidad, la diversidad, es decir, un modelo integral, que este enfocado en incidir todos los valores humanos que permitan comprender el mundo y transformarlo mediante el diálogo y la participación. Para obtener esos resultados, se propone herramientas creativas, las cuales busquen desafiar la capacidad del discente, de ese modo él puede fortalecer su creatividad, y así empezará a generar ideas innovadoras (Ministerio de Educación del Ecuador, 2020b, p. 10).

\section{Recomendaciones para docentes}

Es adecuado que los docentes trabajen con sus estudiantes de manera lúdica, brinden apoyo emocional y propuestas de trabajo que les brinden fortalecer el uso de todos los recursos que tengan a la mano. También es necesario que los docentes, recomienden a los estudiantes si lo consideran conveniente, que estos últimos, generen un diario personal, esta es una experiencia liberadora que les permite expresar sus emociones, las cuales afloran en la situación actual. De la misma forma, se requiere que en el aula se haga actividades recreativas: lecturas, actividades lúdicas y actividades físicas, las cuales permiten un buen uso del tiempo libre y la recreación de toda la familia en conjunto. (Ministerio de Educación del Ecuador, 2020b, p. 12).

La lectura es una de las herramientas pedagógicas más valiosas en todo momento, pues gracias a ella, se puede orientar a los dicentes para lograr enfrentar cualquier crísis, es así, que mediante la lectura se puede expresar con coherencia y lucidez los hechos, emociones y reacciones. Todo esto permite que la comunidad educativa logre vincularse 
y compartir momentos de sosiego y bienestar colectivo. Lo anteriormente dicho, es posible cuando se logra motivar a la lectura, y no se la ve como un acto de obligación, por lo tanto es necesario que las lecturas sean vinculadas a los intereses, las afinidades y las inquietudes de los estudiantes. (Ministerio de Educación del Ecuador, 2020b, p. 12).

Es recomendable que también se envíe un comunicado a los padres de familia, en el que se informe sobre las actividades que van a realizar en el día, con lo cual se tiene una comunición más fluida entre los docentes y los padres, de esa forma se lograría trabajar en conjunto y obtener mejores resultados académicos.

\section{Inclusión de herramientas tecnológicas para un aprendizaje significativo}

Con lo antes expuesto es necesario que el sistema educativo sufra un cambio radical hacia la transformación de la educación mediante la inclusión de herramientas tecnológicas para un aprendizaje significativo, pero debe ser un cambio de modelo que incorpore no solo lo que se crea adecuado desde un punto de vista pedagógico, sino por ejemplo integrar aristas que permitan incluso un desarrollo social sostenible, como lo indica Rojas-Londoño, (2019), es aquí cuando nace la imperante urgencia de incorporar al desarrollo social sostenible en un contexto dentro del campo educativo, mediante un enfoque pedagógico que tenga una visión completa de trabajo multi, inter y transdisciplinario, permitiendo implementar mediante acciones concretas la sostenibilidad empoderada en la sociedad del conocimiento y un modelo educativo eficaz y actualizado a las tendencias mundiales. (pp. 2-3).

La incorporación de las herramientas tecnológicas con efectividad conlleva analizar metodologías interactivas como lo propone el flipped learning y su proceso de clase invertida que, ha sido reconocida por los educadores como un enfoque educativo innovador y efectivo. Derriba totalmente la instrucción tradicional al cambiar el tiempo de instrucción en clase con el tiempo de práctica en el hogar. Si bien se ha identificado la efectividad del aula invertida, también se han señalado los desafíos de aplicarlo a los entornos escolares, como la necesidad de diseños de aprendizaje efectivos en clase y la necesidad de ayudar a los estudiantes a aprender en el hogar y en contextos escolares (Hwang, Lai \& Wang, 2015, p. 5).

El aprendizaje significativo mediante la utilización de recursos tecnológicos que se dividen en tres componentes interdependientes, Tecnologías de la Información y Comunicación - TIC, las Tecnologías del Aprendizaje y del Conocimiento - TAC y complementadas para un engrane metodológico, las Tecnologías para el Empoderamiento y la Participación-TEP, necesitan incluso una nueva visión un nuevo paradigma que integre los componentes necesarios para una formación integral, es así que, Mármol-Jaramillo, Rojas-Londoño, (2020) señalan que, la socioformación se orienta a la solución de problemas abordando retos del desarrollo social sostenible, concibe la formación de personas integras comprometidas a satisfacer lo que demande la sociedad para mejorar las condiciones de vida sobre la base de un trabajo colaborativo y el pensamiento complejo en la consecución de un proyecto ético de vida; y, por tanto, en estrecha vinculación como actores principales los propios involucrados en la necesidad por resolver. En ese sentido, la socioformación presenta un nuevo enfoque en el fomento de la participación ciudadana para abordar la sociedad del conocimiento. (p. 3).

Cuando las TE se utilizan como herramienta para apoyar los procesos de enseñanza aprendizaje, con el transcurso del tiempo la definición cambia y se convierte en E-learning, que es el uso de la tecnología como una metodología tal como lo enuncia Adell en su libro, "El término E-Learning proviene del ámbito o campo de la formación profesional que se adapta para las aplicaciones educativas en las nuevas tecnologías de la información y comunicación" (Adell, 2009), se la utiliza para romper el paradigma de la educación presencial y crear espacios a los cuales cualquier persona podrá asistir desde diferentes partes del mundo y así recibir los conocimientos en las diferentes ofertas educativas y de capacitación.

Esto ha provocado que los docentes incluyan dentro del proceso de enseńanza aprendizaje actual, a raíz del COVID-19, una variedad herramientas tecnológicas entre plataformas y recursos digitales, tanto lúdicos como técnicos, en cada uno de los 
momentos didácticos, y tener que adaptar el currículo presencial a uno virtual para alcanzar un aprendizaje significativo transversal y complementario a la realidad que vive la humanidad.

A continuación, se describirán las herramientas tecnológicas que están siendo más utilizadas en el ámbito educativo.

\section{Las plataformas más utilizadas desde la virtualidad}

Es necesario rescatar que los docentes no utilizan únicamente una herramienta para brindar sus clases, pues ellos buscan hacer sus clases interactivas, dinámicas e interesantes para captar la atención de sus discentes. Es así que diversifican los procesos de intercambio (Ardini, 2020).

Sobre las herramientas más utilizadas un $67.6 \%$ de los docentes favorecen el uso de Whatsapp en sus clases. 66,4 emplean el uso de aulas virtuales como Moodle, Microsoft Teams, Edmodo, etc; 61,3\% usa la plataforma de Videos conferencias Zoom, Google Meet, Youtube, etc; un 22.5\% eligieron el uso de Facebook u otra red social; 11, 4\% utilizan murales digitales como: Genial.ly, Mural.ly; mientras para evaluar e interactuar con los estudiantes se utilizan herramientas como Kahoot y Quiziz (Ardini., 2020).

\section{Plataforma de aprendizaje Moodle}

Una de las plataformas de software libre Moodle, más utilizadas en la pandemia, y la cual nos brinda la factibilidad de crear, administrar los cursos de una manera sencilla y organizada. "Moodle (Modular Object-Oriented Dynamic Learning Enviroment) o Entorno Modular Dinámico Orientado a Objetos de Aprendizaje, consiente la creación de cursos y sitios web basados en Internet, esta fue creada en 1999 por Martin Dougiamas, profesor en la Universidad Australiana de Curtin y está inspirada en la pedagogía constructivista social, la cual plantea la idea de que el conocimiento se va construyendo por el estudiante a partir de su participación activa en el proceso y en relación con su entorno social" (Valenzuela-Zambrano, 2013)

Esta plataforma es de fácil uso y cuenta con toda una comunidad cibernética que va actualizando de manera regular todas nuevas tendencias de la web. 2.0 para hacer de Moodle una herramienta por excelencia que permite embeber otras herramientas para tener un proceso escolástico dinámico y estructurado. Al usar este tipo de entornos de aprendizaje, el discente se desarrolla tanto en lo personal como en lo profesional en colaboración con otras personas y lo más importante, aprende a aprender.

\section{Comunicación Red Social WhatsApp}

En la actualidad, por los motivos de emergencia sanitaria, las vías que han tenido relevancia son las redes sociales: WhatsApp y Facebook son aplicaciones que superan los 1000 millones de usuarios a nivel mundial.

Estas aplicaciones en época del Coronavirus, han servido al maestro para aproximar los conocimientos a sus estudiantes. Si bien es cierto en las instituciones privadas, el uso de plataformas es lo más común, en la mayor parte de los sectores poblacionales no se cuenta con estas herramientas, y menos pensar que los padres de familia tengan equipos tecnológicos que ayuden al estudiante con su proceso de enseñanza- aprendizaje. Aunque se ponga en duda, el WhatsApp por su mensajería instantánea ha servido como nexo entre estudiantes, padres y maestros. Estudios de la Universidad del Istmo, indica que esta aplicación propicia y ayuda a consolidar el trabajo colaborativo, la transmisión de información; más aún si es utilizada en el campo de la educación, si bien permite la construcción del aprendizaje, no es tan efectiva y recomendable, pero es fundamental para mantener línea directa de comunicación (Rojas-Londoño. 2019).

Las redes sociales utilizadas como herramientas de Tecnología Educativa (TE), permiten dar clases de manera sincrónica a aquellos estudiantes que no tienen una laptop o una Tablet y que solo cuentan con teléfono móvil. Con ellas, los docentes buscan la manera de ayudar a sus estudiantes a adaptarse a la situación actual y de esa forma romper las barreras que les dificultan su proceso de aprendizaje.

\section{Cuestionarios con Kahoot}

Las Tecnologías Educativas generan cambios en la forma de dar clases, y los procesos de enseñanza aprendizaje también están siendo modificados, con lo que, gracias a las TE el estudiante participa activamente en su proceso de formación. Kahoot 
es una herramienta dinámica de juegos, los cuales brindan beneficios para que los estudiantes se sientan incluidos en el mismo y temporalmente se convierte en un espectáculo competitivo, todo esto, motiva a los discentes para que se involucren activamente (Fuentes et al., 2016).

Los estudiantes pueden sentir que aprender es divertido ya que hay 3 características en Kahoot, el reto que existe para el estudiante, se da una sensación de fantasía en que salir siempre victorioso es posible y sobre todo, impulsa a que haya la curiosidad en el estudiante (aprender para dar una buena respuesta). Además, los discentes tienen interés de comprender su error, si es que lo hubo, puesto que este programa da retroalimentación a todo el equipo de trabajo de modo que comprenden su error y aprenden del mismo. Kahoot sirve a los docentes en clase para diversas actividades: permite realizar una evaluación de la materia recién facilitada, permite al docente valorar los conocimientos previos antes de abordar un nuevo tema y también permite ver cómo se está dando la evolución en los conocimientos de los estudiantes, ya que guarda el resultado que han obtenido luego de realizar la evaluación (Fuentes et al., 2016).

Esta plataforma ha sido muy utilizada en las clases presenciales desde su creación en el 2012 y desde el 2016 ha generado muchos más estudiantes deseosos de jugar (Fuentes et al., 2016). Y en el Ecuador, a inicios de la cuarentena, esta aplicación, a servido para evaluar e incentivar a los estudiantes a dar todo de sí, y permitir la integración del grupo.

\section{Creación de contenidos con Genial.ly}

Es una plataforma gratuita en español para la gamificación en el ámbito educativo puesto que permite interactuar, dar animación y genera un diseño atractivo, el cual llama la atención de los discentes. La plataforma es diseñada por una empresa espańola, la cual está consciente de que la información tiene que ser dinámica e interactiva, pues ayuda a captar la atención de la audiencia. Genial.ly es una plataforma de fácil acceso, la cual permite crear contenidos atrayentes y que motivan a los estudiantes, es decir es un espacio de aprendizaje que emplea las TE para mediar la construcción del conocimiento entre el discente y el docente (Peña-Cabanas, 2017).
La plataforma brinda plantillas, animaciones y diseños que, desde una pedagogía enfocada hacia el aprendizaje significativo de los estudiantes, transforma la forma de dar clases con el apoyo de presentaciones similares a las diapositivas de PowerPoint, lo que brinda alternativas para que de forma creativa el docente actualice, facilite e innove en sus clases.

\section{Interactividad por Zoom}

Es una aplicación de videoconferencia con mensajería en tiempo real e intercambio de contenido, esta plataforma es de fácil uso y su configuración está al alcance de todos los miembros de la comunidad educativa, en la modalidad gratuita permite hasta una participación de 100 usuarios. Sin embargo, Zoom ha tenido problemas con la privacidad y seguridad, situación que se ha estado trabajando para mejorar. Para contrarrestar todo eso, Zoom ha implantado la "sala de espera", la cual permite que el anfitrión logre identificar a cada usuario que ingrese a la reunión, también implantó que solo el anfitrión tenga la capacidad de compartir pantalla y que éste sea el encargado de delegar funciones dentro de su aula virtual. En definitiva, se considera que Zoom con esas mejoras permite cubrir sus contenidos, y así es una plataforma amigable para las clases escolares (Centro Criptológico Nacional, 2020)

Esta plataforma permite que el docente controle la pantalla de su estudiantes, brinde explicaciones sobre algo que no se comprende y organice la interacción entre varios compañeros de clases. Esta plataforma ha facilitado brindar clases durante todo el año escolar y lo seguirá haciendo ya que con la nueva normalidad, el regreso a clases no parece estar cerca. Algunos países que han acelerado el regreso a las clases presenciales han visto cómo los contagios de la Covid-19 se ha propagado, es por eso que este tipo de transformaciones educativas ha llegado para quedarse como parte de las clases en línea y las actividades sincrónicas y asincrónicas, que llevan a cabo docentes y estudiantes, quienes tendrán que acostumbrarse a este cambio que en cierta manera será prolongado. (Centro Criptológico Nacional, 2020)

\section{Una de la más usadas Microsoft Teams}

De la misma forma, con la propagación de la pan- 
demia muchos centros educativos empezaron a utilizar Microsoft Teams, una plataforma del Paquete de Office y que permite unir a los docentes con sus estudiantes. La aplicación tiene las alternativas de realizar conversaciones, reuniones, archivos y varias aplicaciones las cuales ofrecen seguridad, puesto que están seriadas. Permite que los estudiantes y los profesores trabajen en conjunto tanto en proyectos, como tareas de grupo y correcciones de ejercicios. El docente decide quién tiene acceso al material, mientras que los estudiantes tienen permiso de escritura en áreas concretadas por el maestro (Romero, 2020)

La plataforma Microsoft Teams permite el trabajo sincrónico o asincrónico orientado por el docente, lo que permite que los estudiantes sean agentes activos en su aprendizaje, que se motivan por investigar y esclarecer las dudas que tienen en sus conocimientos. Esta TE hace que el estudiante pase de ser un receptáculo de información a convertirse en un ser ávido e inquieto, que sale de su estado estático; mientras que el docente pasa de ser el centro del proceso de enseñanza-aprendizaje a mediador y orientador de sus estudiantes.

\section{Conclusiones}

La política educativa debe considerar de manera apremiante la capacitación a los docentes en innovación educativa, así como también los docentes de manera personal y voluntaria deben buscar formación que incluya el manejo de herramientas educativas digitales para mejorar los procesos de enseñanza aprendizaje, por lo que se debe replantear la educación en el sentido en el que ha venido desarrollándose, se debe considerar de manera ineludible el impulso del uso de herramientas tecnológicas como medio de enseñanza - aprendizaje que sean acordes a la era en la que estamos viviendo, de igual forma se debe incluir asignaturas dentro de la malla curricular permitan el perfeccionamiento de prácticas habilidosas en el manejo de softwares educativos.

El virus COVID-19, ha modificado muchas cosas en la actualidad. Las clases son virtuales y las plataformas que permiten una interacción en vivo son utilizadas con frecuencia (Zoom y Microsoft Teams), todas estas herramientas tecnológicas han permitido que los estudiantes puedan seguir formándose académicamente. Por lo que es necesario seguir capacitando a docentes y estudiantes en el dominio de estas plataformas. En el Ecuador muchas familias no tienen acceso a la conectividad por lo que el uso de plataformas virtuales fue escaso, sin embargo, las redes sociales como Whatsapp y Facebook fueron un pilar importante para continuar con la educación desde casa, ya que se convirtieron en una herramienta clave de conexión entre los docentes y los estudiantes, además que son de fácil uso lo que posibilitó la practicidad para llevar la enseñanza a cada una de las familias.

Las herramientas tecnológicas para un aprendizaje significativo descritas, coadyuvan a que los estudiantes sean entes activos en su aprendizaje, que se motiven a investigar y a generar sus propios conocimientos, que no estén supeditados a la presencia del docente, recordando que éste es un guía que orienta el proceso de enseñanza - aprendizaje, pero que al final quien construye sus conocimientos es el discente, y de esa forma él está más cerca de aprender a aprender.

La cuarentena ha forjado una brecha entre todos los miembros de la colectividad educativa, haciendo que la comunicación entre todos sea indispensable. El constante diálogo permite generar una interacción adecuada de modo que todos tengan los mismos objetivos como potenciar los conocimientos de los estudiantes y sobre todo su equilibrio emocional. La educación virtual permite romper las barreras geográficas, conlleva a incluirse en una nueva cultura de participación y aprendizaje al llegar a un sinnúmero de personas en el mundo, las TIC son herramientas preferenciales que facilitan el acceso a la información y a la comunicación, permitiendo multiplicidad de tareas, el Internet y otros medios de comunicación han permitido continuar con los procesos de enseńanza aprendizaje y así garantizar el derecho a la instrucción de infantes $y$ adolescentes 


\section{REFERENCIAS BIBLIOGRÁFICAS}

Adell, M. A. (2009). Tecnología Educativa. La formación del profesorado en la era de Internet. En M. A. Segura, Tecnología Educativa. La formación del profesorado en la era de Internet. Editorial Aljibe, Málaga: España.

Alvites-Huamaní, C. (2020). COVID-19: Pandemia que impacta en los estados de ánimo. CienciAmérica, 9 (2). http://dx.doi.org/10.33210/ca.v9i2.327

Ardini c., Herrera, M., González, A. \& Secco N. E. (2020). Docencia en tiempos de coronavirus: una mirada al trabajo docente y la experiencia educativa en entornos virtuales en el marco del ASPO por la pandemia COVID-19. Publicación Digital. Mutual Conexión. Facultad de Ciencias de la Comunicación Universidad Nacional de Córdoba. Córdoba, Argentina. 2020.

Banco Interamericano de Desarrollo. (2018, 18 de agosto). Gestión Digital. Recuperado de https://www.revistagestion. ec/index.php/sociedad-analisis/la-desercion-escolar-secundaria-un-reto-para-ecuador-y-america-latina.

Buxarrais E., M. R., \& Ovide, E. (2011, 5 de noviembre). El impacto de las nuevas tecnologías en la educación en valores del siglo XXI. Sinética. Recuperado de http://www.sinectica. iteso.mx/index.php?cur=37\&art=37_11

Centro Criptológico Nacional. (2020, 22 de mayo). El uso de Zoom y sus implicaciones para la seguridad y privacidad. Recomendaciones y buenas prácticas. Obtenido de https:// www.ccn.cni.es/index.php/es/docman/documentos-publicos/abstract/215-abstract-el-uso-de-zoom-y-sus-implicaciones-para-la-seguridad-y-privacidad-recomendaciones-y-buenas-practicas/file

Cotino, L. (2020). La enseñanza digital en serio y el derecho a la educación en tiempos del coronavirus. REVISTA DE EDUCACIÓN Y DERECHO, 1-27. doi:https://doi. org/10.1344/REYD2020.21.31283

Global Digital. (2020, 30 de enero). El Uso de las Redes Sociales Abarca Casi la Mitad de la Población Mundial.

Dillon, F., Rojas, D., Robalino, J., \& Maldonado, M. (2020). Autoevaluación y acreditación universitaria en el contexto ecuatoriano. Perspectivas de análisis y mejora. Ciencia y Educación, 4(2), 27-37. https://doi.org/10.22206/ cyed.2020.v4i2.pp27-37

Fuentes, M. M., Andrino, M. M., Pascual, M. A., Martín, A. R., García, C. S., \& López, M. T. (2016). El aprendizaje basado en juegos: experiencias docentes en la aplicación de la plataforma virtual "Kahoot". Alicante, España. doi:97884-608-7976-3

González, J. A. G., Londoño, O. D. R., Vásconez, L. A. C., \& Cerón, C. P. C. (2019). El impacto de la psicología en el ámbito educativo. RECIMUNDO: Revista Científica de la Investigación y el Conocimiento, 3(2), 543-565.

Hernández Sampieri, R. (2010). Metodología de la Investigación. México D.F.. Interamericana Editores S.A.
Hwang, G. J., Lai, C. L., \& Wang, S. Y. (2015). Aprendizaje invertido sin interrupciones: un aula invertida mejorada con tecnología móvil con estrategias de aprendizaje efectivas. Revista de computadoras en educación, 2 (4), 449-473.

INEC. (2018). Ecuador en cifras. Recuperado de https:// www.ecuadorencifras.gob.ec/documentos/web-inec/Estadisticas_Sociales/TIC/2018/201812_Principales_resultados_ TIC_Multiproposito.pdf

Mármol-Jaramillo, G., \& Rojas-Londoño, O. (2020). La Participación Ciudadana en América Latina: Un Enfoque Desde la Socioformación. En J. Luna-Nemecio (Coord.), Memorias del Quinto Congreso Internacional de Investigación en Socioformación y Sociedad del Conocimiento (CISFOR-2020). Congreso conducido por el Centro Universitario CIFE, Cuernavaca, México. Recuperado de: https://cife. edu.mx/recursos

Ministerio de Educación del Ecuador . (2020a, 12 de marzo). Comunicado Oficial Suspensión de las actividades académicas para los estudiantes para precautelar la salud de la comunidad educativa. Recuperado de https://educacion. gob.ec/comunicado-oficial-suspension-de-las-actividades-academicas-para-los-estudiantes-para-precautelar-la-salud-de-la-comunidad-educativa/

Ministerio de Educación del Ecuador. (2020b). Plan Educativo: aprendamos juntos en casa. Quito, Pichincha, Ecuador.

OEI-Organización de Estados Iberoamericanos para la Educación, la Ciencia y la Cultura, (2020). Efectos de la crisis del coronavirus en la Educación. Informe OEI, Madrid, España.

Rojas-Londoño, O. (2019). El desarrollo social sostenible: el eje de una nueva visión educativa. En L. G. Juárez-Hernández (Coord.), Memorias del Cuarto Congreso Internacional en Socioformación y Sociedad del Conocimiento (CISFOR-2019). México: CIFE.

Romero, A. A. (2020, 13 de abril). Microsoft Teams: Guía de iniciación y tutorial. Obtenido de https:/www.profesionalreview.com/2020/04/13/microsoft-teams-guia-de-iniciacion-y-tutorial/

Saavedra, J. (2020, 30 de Marzo). Coronavirus: La respuesta del Grupo Banco Mundial ante la emergencia mundial de hacer frente a la pandemia.

Valenzuela-Zambrano, B. P.-V. (2013). Aprendizaje autorregulado a través de la plataforma virtual Moodle. Educación y Educadores, 16(1), 66-79.

Vera-Villarroel, P. (2020). Psicología y COVID-19: un análisis desde los procesospsicológicos básicos.

Cuadernos de Neuropsicología/Panamerican Journal of Neuropsychology, 14(1). 